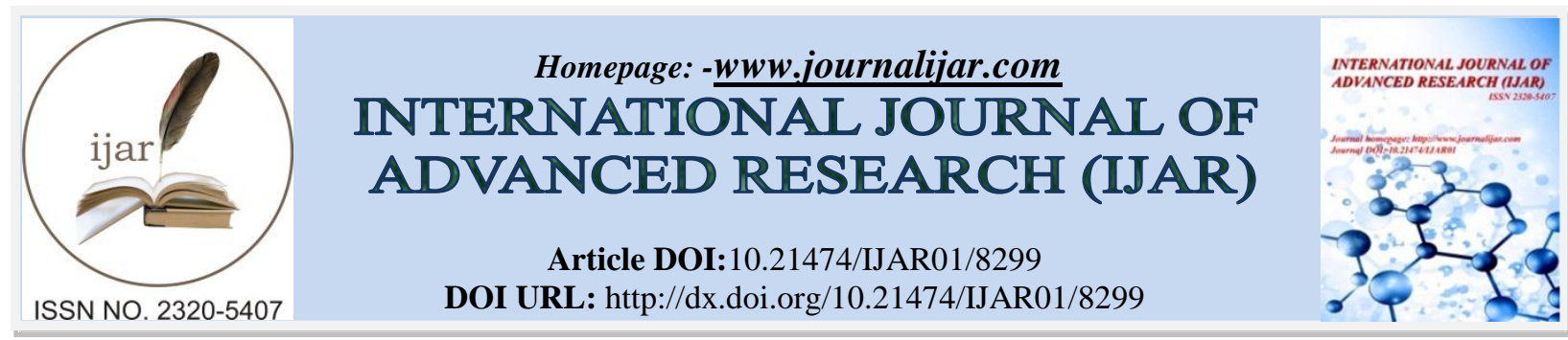

RESEARCH ARTICLE

\title{
EFFECTS OF WHOLE BODY VIBRATION USING VIBRATORY PLATFORMSON REHABILITATION OF PATIENTS SUBMITTED TO SURGERY FOR ANTERIOR CRUCIATE LIGAMENT INJURY.
}

Luana Ribeiro Nogueira and Laila Cristina Moreira Damazio.

Departament Medicine/UFSJ/Praça Dom Helvécio, 74, Fábricas, São João del-Rei, MG - CEP: 36301-160.

\section{Manuscript Info}

\section{Manuscript History}

Received: 01 November 2018

Final Accepted: 03 December 2018

Published: January 2019

Key words:-

ACL injury, ligaments, vibration, quadriceps muscle, ischiotibial muscle.

\begin{abstract}
Anterior cruciate ligament (ACL) reconstruction is performedin approximately 200,000 athletes in the United States per year. The main changes are clinical deficits in postural control, proprioception, and muscular strength. Whole body vibration (WBV) is an alternative method for neuromuscular stimulation that promotes muscle strength gain. There are two types of vibrations, direct and indirect. The goal of the present study was to evaluate the effects of WBV using vibratory platformson rehabilitation of patients submitted to surgery for ACL injury, in order to contribute to the adoption of this therapeutic procedure by healthcare professionals. A systematic literature review was performed dusing the following databases: SciELO, BIREME, PubMed, and ScienceDirect. It was concluded that WBVtraining promoted positive rehabilitation outcomes in patients with ACL injury, mainly muscle strength and functionality gain.
\end{abstract}

Copy Right, IJAR, 2017,. All rights reserved.

\section{Introduction:}

The anterior cruciate ligament (ACL) is composed of two bundles, one of which is anteromedial, and the other posterolateral, named according to tibial insertion sites. Each bundle has a unique functional quality which, in combination, contribute to knee stability, given that the ACL is the main inhibitor of anterior instability and internal rotation of the tibia. The rupture of this ligament is considered one of the most common injuries, with approximately 200,000 injuries occurring in the United States per year. ${ }^{1-5}$

The mechanism of ACL injury occurs by means of the anterolateral force of the proximal tibia (20 to 40 degrees of knee flexion) that induces coupled internal rotation, provoking anterolateral rotatory instability (ALRI). When this mechanism takes place in the tibial plateau, the posterolateral structures that cross the joint line will be able to resist the movement and the excursion of bones can occur with later combined injury. This type of injury mainly affects young and active individuals. ${ }^{2,6}$

When an ACL injury occurs, there is an abnormal afferent dischargethat alters the excitability of the reflex pathways in the spinal cord, reducing the sensory feedback in the mechanoreceptors of the knee extensors, thus preventing the muscles from being activated. The lack of activation of this muscle cluster changes the biomechanics of articulation and causes instability. Atrophy and fragility of the quadriceps muscle provoked by ACL injury have been reported as one of the greatest challenges during the rehabilitation of patients with reconstructive surgery. ${ }^{5,10-12}$

Corresponding Author:-Laila Cristina Moreira Damázio.

Address:-Departament Medicine/UFSJ/Praça Dom Helvécio, 74, Fábricas, São João del-Rei, MG CEP: $36301-160$. 
ACL reconstruction is used in approximately 200,000 athletes in the United States per year. In the $42^{\text {nd }}$ Brazilian Congress of Orthopedics and Traumatology, 2010, Arliani et al. conducted a study with 226 surgeons. These authors reported that flexor tendon grafting (gracilis and semitendinosus) was the most used (82.3\%), followed by the central third of the ipsilateral patellar tendon (53.5\%). In the same study, physiotherapy was chosen by $61.9 \%$ of the surgeons, and $65.9 \%$ referred the patients to rehabilitation one week after surgery. ${ }^{6}$

The main changes found in individuals with ACL injury are clinical deficits in postural control, proprioception, and muscular strength. These deficits are restored three month after surgery. This fact, together with the advances in the surgical technique and graft fixation, explains the recommendation for rehabilitation right after surgery. ${ }^{3,13-15}$ Rehabilitation at this time is considered crucial for patients' success; however, it is necessary to take into consideration whether excessive anterior slippage and internal rotation after ACL reconstruction remain elevated. ${ }^{2,16}$

The main objectives of physiotherapy are graft protection, muscle strengthening, neuromuscular control, joint proprioception, and postural control aimedat promoting stability, functional capacity, and motor coordination in the patients. ${ }^{14,17}$ This way,the deficits of functionality should be measured in detail, so that the rehabilitation program can provide appropriate functional outcomes. ${ }^{10}$

The current ACL rehabilitation treatments include immediate movement, early partial and total weight discharge after six to eight weeks, muscle strengthening with closed kinetic chain exercises, functional activities, and proprioceptive and neuromuscular exercises. ${ }^{5,18,19}$ The main methods and therapies used during the preoperative stage are exercises for strengthening the quadriceps, neuromuscular electrical stimulation, cryotherapy, and compression and elevation of the limbs. On the other hand, during the postoperative stage (0-4 weeks), the techniques used are cryotherapy, weight discharge using belts and crutches, progressive gait training, and patellar mobilizations. Finally, during the strengthening stage (4 weeks to 6 months), the techniques used are specific exercises to avoid compensatory mechanisms and incorrect overload, and neuromuscular and cardiopulmonary training. The progression of treatment should include exercises with greater load, walking, running, and dynamic jumping activities. At the end of treatment, advanced body pivot and plyometric training should be added. ${ }^{5}$

Whole body vibration (WBV) emerged slowly as an alternative method for neuromuscular stimulation, being used more and more in physiotherapy clinics and fitness centers. The appliances feature constant bell-shaped vibrations. There are two types of vibrations, namely: direct, whichis in direct contact with the muscles/tendonsat the moment of application; and indirect, in which the vibrations occur in a dissipated way through the organs, muscles, and systems in contact with distal limbs. There are two types of vibratory platforms. One of them moves vertically around a central axis in uniform manner, and the other moves in the direction of the structures that are closest to the platform. The adjustable parameters are: vibration amplitude, which variesfrom 2 to $10 \mathrm{~mm}$; frequency, ranging from 12 to $50 \mathrm{~Hz}$; and exposure time, varying from 30 to 60 seconds. ${ }^{18-21}$

According to Bastian et al. ${ }^{12}$ and Giambioni et al. ${ }^{20}$ the vibratory stimulation training produces an increase in the activation of neuromuscular mechanisms, maximizing the response to stretch reflex. As a result, there is an increase in the muscle perimeter and strength, recovery of motor coordination, mobility, balance, better flexibility, and power. ${ }^{12,18,20}$ Therefore, WBV therapy is a resource of great potential for rehabilitation of patients with ACL reconstruction. Previous studies have indicated this type of therapy as an alternative method to accelerate patients' rehabilitation and return to daily activities. ${ }^{3,12,16}$ From this perspective, the goal of the present study was to assess the effects of WBVusing vibratory platformson rehabilitation of patients submitted to surgery for ACL injury.

\section{Method:}

The search was carried out in SciELO, BIREME, PubMed, and ScienceDirect databases with the purpose of finding articles/studies that had addressed the effects of WBV training on patients submitted to surgery for ACL injury. We used the following keywords: (1) ACL injury; (2) WBV; (3) vibratory platform; (4) quadriceps; and (5) ischiotibials. The studies selected were published from 2001 to 2017.

We selected original clinical studies and/or reviews and books written in Portuguese, English, and Spanish addressing participants with ACL injury, physiotherapy interventions, and treatments usingWBV training. The articles excluded were: literature reviews; those using interventions in addition to WBV training and physiotherapy; others that assessed participants without ACL injury; studies describing treatments that had not been supervised by physiotherapists; and those that had not addressed the referred topic in a clear way. In order to determine the 
inclusion and exclusion criteria, we performed a partial reading of the abstracts of thestudies. Subsequently, we selected the materials that presented complete methodology and the interventions performed. The information collected included: population; group distribution; methods used; application time; outcomes; and authors' final conclusions.

\section{Results:}

From the 571 studies found, we selected 79 to be read in full to determine their eligibility according to the inclusion and exclusion criteria. After the application of the criteria, 24 studies were selected, and only six of them were used for the variables under discussion, as illustrated in the table below:

Table 1. Selection of studies according to the inclusion and exclusion criteria.

\begin{tabular}{|c|c|c|}
\hline \multirow{2}{*}{ Identification } & $\begin{array}{c}\text { 571 studies found in SciELO, } \\
\text { PubMed, BIREME, and } \\
\text { ScienceDirect databases }\end{array}$ \\
\hline Selection & & 515 studies after excluding duplicates \\
\cline { 2 - 3 } & & 515 titles and abstracts analyzed \\
\cline { 2 - 3 } & & 492 studies excluded \\
\hline Eligibility & $\begin{array}{c}\text { Combination of extended therapy } \\
\text { with no supervised physiotherapy }\end{array}$ \\
\cline { 2 - 3 } & $\begin{array}{c}\text { 24 studies included and only } 6 \text { used } \\
\text { in the results and discussion }\end{array}$ \\
\hline
\end{tabular}

Table 2. Results of the selected studies.

\begin{tabular}{|c|c|c|c|c|}
\hline STUDY & AUTHOR(S) & METHOD & $\begin{array}{c}\text { PARAMETER } \\
\text { VARIABLES }\end{array}$ & RESULTS \\
\hline $\begin{array}{l}\text { Whole Body Vibration } \\
\text { Expedites and } \\
\text { Improves Recovery of } \\
\text { Anterior Cruciate } \\
\text { Ligament (ACL) } \\
\text { Rupture and } \\
\text { Subsequent } \\
\text { Arthroscopic } \\
\text { Reconstructive } \\
\text { Surgery. }\end{array}$ & $\begin{array}{l}\text { Bastian JD, Franz } \\
\text { W, Klinik L }\end{array}$ & $\begin{array}{l}\text { Sample of } 16 \\
\text { individuals with } \\
\text { ACL injury } \\
\text { divided into two } \\
\text { groups: G1 - } \\
\text { WBV + } \\
\text { physiotherapy; } \\
\text { G2 - } \\
\text { physiotherapy. }\end{array}$ & $\begin{array}{l}\text { 10-minute } \\
\text { vibration two } \\
\text { times per week, } \\
\text { included three } \\
\text { weeks after } \\
\text { surgery. }\end{array}$ & $\begin{array}{l}\text { G1 maintained } \\
\text { muscular strength } \\
\text { and leg } \\
\text { perimeter. G2 } \\
\text { exhibited atrophy } \\
\text { and quadriceps } \\
\text { strength loss, } \\
\text { with no recovery } \\
\text { after surgery. }\end{array}$ \\
\hline $\begin{array}{l}\text { Effect of whole body } \\
\text { vibration frequency on } \\
\text { neuromuscular activity } \\
\text { in ACL-deficient and } \\
\text { healthy males. }\end{array}$ & $\begin{array}{l}\text { Giombini A, } \\
\text { Menotti F, Laudani } \\
\text { L, Piccinini A, } \\
\text { Fagnani F, Di } \\
\text { Cagno A, Macaluso } \\
\text { A, Pigozzi F }\end{array}$ & $\begin{array}{l}30 \text { individuals of } \\
\text { which } 15 \text { had } \\
\text { lateral ACL } \\
\text { injury and } 15 \\
\text { were healthy. } \\
\text { Both groups } \\
\text { were submitted } \\
\text { to WBV training. }\end{array}$ & $\begin{array}{l}\text { Vibration } \\
\text { amplitude: } \\
\text { mm; frequency: } \\
0 \text { to } 45 \mathrm{~Hz}, \\
\text { increased every } \\
5 \text { seconds with } \\
30 \text {-minute } \\
\text { break. }\end{array}$ & $\begin{array}{l}\text { Vibration } \\
\text { frequency of } 30- \\
35 \mathrm{~Hz} \text { promoted } \\
\text { greater } \\
\text { neuromuscular } \\
\text { activation. } \\
\text { Activation in the } \\
\text { ACL group was } \\
\text { greater (20-40 } \\
\text { Hz) than in the } \\
\text { healthy group. }\end{array}$ \\
\hline
\end{tabular}




\begin{tabular}{|c|c|c|c|c|}
\hline $\begin{array}{l}\text { Whole Body Vibration } \\
\text { Exercise Protocol } \\
\text { versus a Standard } \\
\text { Exercise Protocol } \\
\text { after ACL } \\
\text { Reconstruction: A } \\
\text { Clinical Randomized } \\
\text { Controlled Trial with } \\
\text { Short } \\
\text { Term Follow-Up }\end{array}$ & $\begin{array}{l}\text { Berschin G, } \\
\text { Sommer B, Behrens } \\
\text { A, Sommer HM }\end{array}$ & $\begin{array}{l}40 \text { individuals } \\
\text { with ACL injury } \\
\text { divided into two } \\
\text { groups: GI - } \\
\text { WBV; and G2 - } \\
\text { standard control. }\end{array}$ & $\begin{array}{l}\text { Vibration } \\
\text { amplitude: 5-9 } \\
\text { mm; frequency: } \\
\text { 10-15 Hz. After } \\
\text { the fifth week, } \\
\text { the frequency } \\
\text { was } \\
\text { progressively } \\
\text { increased up to } \\
30 \mathrm{~Hz} \text {. }\end{array}$ & $\begin{array}{l}\text { Both groups } \\
\text { exhibited } \\
\text { significantly } \\
\text { increased knee } \\
\text { flexors and } \\
\text { extensors } \\
\text { strength, with no } \\
\text { significant } \\
\text { difference. } \\
\text { However, length } \\
\text { of recovery in G1 } \\
\text { was shorter than } \\
\text { in G2. }\end{array}$ \\
\hline $\begin{array}{l}\text { Effects of early whole- } \\
\text { body vibration } \\
\text { treatment on knee } \\
\text { neuromuscular } \\
\text { function and postural } \\
\text { control after } \\
\text { anterior cruciate } \\
\text { ligament } \\
\text { reconstruction: a } \\
\text { randomized } \\
\text { controlled Trial }\end{array}$ & $\begin{array}{l}\text { Pistone EM, } \\
\text { Laudani L, } \\
\text { Camillieri G, Cagno } \\
\text { AD, Tomassi G, } \\
\text { Macaluso A, } \\
\text { Giombini A }\end{array}$ & $\begin{array}{l}\text { Sample of } 34 \\
\text { individuals with } \\
\text { ACL injury, } \\
\text { divided into two } \\
\text { groups: G1- } \\
\text { WBV + } \\
\text { physiotherapy; } \\
\text { G2 - } \\
\text { physiotherapy. }\end{array}$ & $\begin{array}{l}\text { Vibration } \\
\text { amplitude: } 2 \\
\text { mm; gradual } \\
\text { frequency: } 0-50 \\
\text { Hz, increased } \\
\text { every } 5 \text { seconds } \\
\text { with } 35 \text {-minute } \\
\text { break. }\end{array}$ & $\begin{array}{lr}\text { G1 individuals } \\
\text { exhibited } \\
\text { improved knee } \\
\text { flexors } \\
\text { extensors } \\
\text { strength, and } \\
\text { increased knee } \\
\text { extension in } \\
\text { comparison } \\
\text { G2. }\end{array}$ \\
\hline $\begin{array}{l}\text { Whole-Body and Local } \\
\text { Muscle Vibration } \\
\text { Immediately } \\
\text { Improve Quadriceps } \\
\text { Function in Individuals } \\
\text { With } \\
\text { Anterior Cruciate } \\
\text { Ligament } \\
\text { Reconstruction }\end{array}$ & $\begin{array}{l}\text { Pamukoff DN, } \\
\text { Pietrosimone B, } \\
\text { Lewek MD, Ryan } \\
\text { ED, Weinhold PS, } \\
\text { Lee DR, Blackburn } \\
\text { JT }\end{array}$ & $\begin{array}{l}20 \text { individuals } \\
\text { with unilateral } \\
\text { ACL injury } \\
\text { assessed before } \\
\text { and after WBV } \\
\text { training. }\end{array}$ & $\begin{array}{l}\text { Vibration } \\
\text { amplitude: } 2 \\
\text { mm; frequency: } \\
30 \mathrm{~Hz} \text {. }\end{array}$ & $\begin{array}{l}\text { A single } \\
\text { vibration session } \\
\text { promoted } \\
\text { improved } \\
\text { function, } \\
\text { strength, } \\
\text { voluntary } \\
\text { activation, and } \\
\text { corticomotor } \\
\text { excitability of } \\
\text { quadriceps in } \\
\text { patients } \\
\text { submitted to } \\
\text { ACL } \\
\text { reconstruction. }\end{array}$ \\
\hline $\begin{array}{l}\text { The Effect of Early } \\
\text { Whole-Body Vibration } \\
\text { Therapy on } \\
\text { Neuromuscular } \\
\text { Control After } \\
\text { Anterior Cruciate } \\
\text { Ligament } \\
\text { Reconstruction } \\
\text { A Randomized } \\
\text { Controlled Trial }\end{array}$ & $\begin{array}{l}\text { Fu CLA,Yung SHP, } \\
\text { Law KYB, } \\
\text { Leung KHH, Lui } \\
\text { PYP, Siu HK, Chan } \\
\text { KM }\end{array}$ & $\begin{array}{l}48 \text { individuals } \\
\text { with ACL injury, } \\
\text { divided into two } \\
\text { groups: G1 - } \\
\text { WBV + } \\
\text { physiotherapy; } \\
\text { and G2 - } \\
\text { physiotherapy. }\end{array}$ & $\begin{array}{l}\text { Vibration } \\
\text { amplitude: } 4 \\
\text { mm; gradual } \\
\text { frequency: } 35- \\
50 \mathrm{~Hz} \text {, increased } \\
\text { every } 5 \mathrm{~Hz} \text {. }\end{array}$ & $\begin{array}{l}\text { G1 exhibited } \\
\text { significant } \\
\text { outcomes } \\
\text { regarding } \\
\text { postural control, } \\
\text { muscle } \\
\text { performance, } \\
\text { single jump, } \\
\text { running, and } \\
\text { length of } \\
\text { recovery in } \\
\text { comparison to }\end{array}$ \\
\hline
\end{tabular}




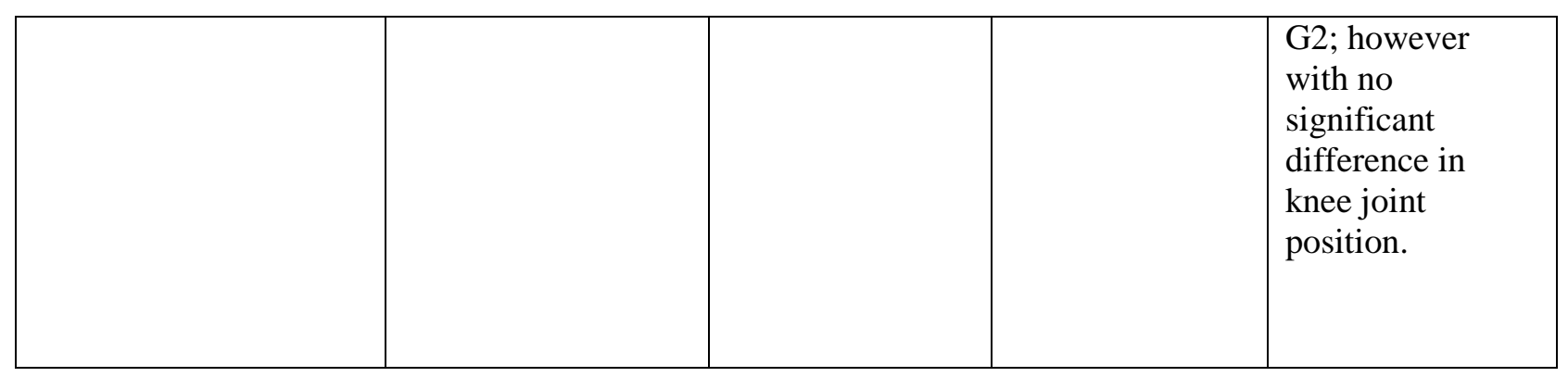

\section{Discussion:}

The goal of the present study was to determine the effects of WBV using vibratory platformson the rehabilitation of patients submitted to surgery for ACL injury. To that end, we assessed scientific studies that evidenced significant benefits of WBV training in muscle strength and functionality gain in those patients. This way, the assessment of the parameters used in those studies becomes important, because they will guide the therapeutic procedures.

Giombini et al., ${ }^{20}$ Pistone et al., ${ }^{3}$ and Pamukoff et al. ${ }^{24}$ used vibration amplitude of $2 \mathrm{~mm}$ in their studies, Fu et al. ${ }^{14}$ and Avelar et al. ${ }^{22}$ used $4 \mathrm{~mm}$, and Berschin et al. ${ }^{17}$ used 5-9 mm. Regarding vibration frequency, Pamukoff et al. ${ }^{24}$ and Avelar et al. ${ }^{22}$ only reporteda frequency of $30 \mathrm{~Hz}$, Pistone et al. ${ }^{3}$ used 0-50 Hz progressively increased every five seconds, Giombini et al. ${ }^{20}$ used0-45 Hz incremented every five seconds, Fu et al. ${ }^{14}$ used $35-50 \mathrm{~Hz}$ increased every 5 $\mathrm{Hz}$, and Berschin et al. ${ }^{17}$ used a lower frequency rate, ranging from 10 to $15 \mathrm{~Hz}$ increased up to $30 \mathrm{~Hz}$. Only Giombini et al. ${ }^{20}$ and Pistone et al. ${ }^{3}$ reported breaks between frequency changes that varied between 5 and 35 seconds. The ideal frequency reported was $30-35 \mathrm{~Hz}$ to improve the activation of the lateral vastus muscle, with positive outcomes in muscle strength and functionality gain.,20

With respect to exposure time, Berschin et al. ${ }^{17}$ performed two to six repetitions of 20-minute muscle exercise, Pamukoff et al. ${ }^{24}$ performed six repetitions of 60 seconds, and Bastian et al. ${ }^{12}$ used 10 -minute vibration. Giombini et al., ${ }^{20}$ Pistone et al., ${ }^{3}$ and Avelar et al. ${ }^{22}$ reported that the participants of the studies remained in squatting position, with 60 degrees knee flexion, barefoot and the feet $28 \mathrm{~cm}$ apart, which was considered the best position for quadriceps muscle activation.

As previously discussed, the fragility of the quadriceps muscle is one of the major challenges during rehabilitation of patients with ACL reconstruction. Thus, to assess the effects of vibratory platformson the treatment, most authors used electromyography of the lateral vastus muscle in the dominant limb, with application of two 4-mm electrodes, at a distance of $20 \mathrm{~mm}$ from each other. ${ }^{3,20,22,24}$

The methods for assessing the effects of WBV using vibration platforms found in the studies were: perimetry; ${ }^{10,12}$ goniometry; $;^{10,14,17}$ strength test; ${ }^{3,17}$ dynamometer; ${ }^{3,10,14,24}$ balance and Lysholm score; ${ }^{3}$ the Hoffmann reflex, which assesses the excitability of the quadriceps motor neurons; ${ }^{24}$ transcranial magnetic stimulation; ${ }^{24}$ jump tests; ${ }^{10,14} \mathrm{knee}$ injury tests; ${ }^{14}$ and self-assessment questionnaires assessing the influence of ACL injury on life in general. ${ }^{10}$

In the study conducted by Bastian et al., ${ }^{12}$ the participants of the WBV group maintained the size and strength of the leg muscle, whereas the group that only performed conventional physiotherapy suffered atrophy and quadriceps strength loss. On the other hand, Krafft et al. ${ }^{10}$ compared a group of individuals with ACL injury and a healthy group, and found that, six months after surgery, the injured legs exhibited greater thickness than the non-injured legs, though with reduced circumference.

Berschin et al. ${ }^{17}$ found significant increases in the strength of the knee extensor and flexor muscles. The group submitted to WBV for rehabilitation exhibited increased isometric knee extension, with a deficit of $31 \%$ in ischiotibial muscles, and $36 \%$ in quadriceps, in comparison to the non-injured legs. The same outcome was observed in the study conducted by Pistone et al., ${ }^{3}$ in which the patients with ACL injury submitted to physiotherapy and vibratory platform obtained improved knee flexors and extensors strength, maintaining these outcomes after three months. In line with the previous outcomes, the authors that used the dynamometer observed similar outcomes with increased strengthof the muscles involved inknee flexion and extension. ${ }^{3,10,14,24}$ 
The results of the assessment of the Hoffmann reflex and transcranial magnetic stimulation in the study conducted by Pamukoff et al. ${ }^{24}$ indicated that WBV improved voluntary activation and corticomotor excitability of the quadriceps muscle after ACL reconstruction, thus benefiting patients' muscle strengthening.

With respect to goniometry and joint mobility, Berschin et al. ${ }^{17}$ observed a small increase in the mobility of the knee joint in the group submitted to vibration treatment using vibratory platforms. However, Fu et al. ${ }^{14}$ found no difference in joint mobility of the groups tested. On the other hand, Krafft et al. ${ }^{10}$ reported positive effects with significant increase in knee flexion and extension; however, the individuals of the treatment group exhibited less mobility than the individuals of the control group when assessed six months after ACL reconstruction.

Another important parameter that improved with rehabilitation using WBV was body balance. Pistone et al. ${ }^{3}$ reported that the static balance scores of the group submitted toWBV improved significantly in comparison to the scores of the group only submitted to conventional physiotherapy.

The study conducted by Fu et al. ${ }^{14}$ indicated better performance in single jump and running among patients submitted to surgery for ACL injury and treated with WBV; however, changes in triple jump were not observed. ${ }^{14}$

The length of recovery during rehabilitation after ACL reconstruction should be considered in sports practice. Berschin et al. ${ }^{17}$ and Fu et al. ${ }^{14}$ found that $\mathrm{WBV}$ is an effective method that reduces the time required for increasing knee muscle strength. ${ }^{14,17}$

According to the studies mentioned above, WBV amplitude of $2 \mathrm{~mm}$ and frequency of $30-35 \mathrm{~Hz}$ are effective in rehabilitating patients submitted to surgery for ACL injury, promoting shorter treatment length and increased muscle strength.

This way, according to Pistone et al., ${ }^{3}$ Fu et al. ${ }^{14}$ and Pamukoff et al., ${ }^{24}$ WBV associated with physiotherapy promotes relevant outcomes in muscular strength, knee stability, balance, postural control, and length of recovery after ACL reconstruction.

This way, the present study demonstrates through the literature review performed that the combination of WBV with conventional physiotherapy has been found to be more effective in rehabilitation than the two methods used separately.

\section{Conclusion:}

It is concluded, that WBV using vibratory platforms as a rehabilitation method for patients submitted to surgery for ACL injury is effective and promotes beneficial effects, mainly relating to quadriceps strength gain. For this reason, it is important to determine the ideal vibration frequency, in order to promote improved muscle activation. Therefore, WBVshould be included as a complementary method for rehabilitation and not as a substitute for treatment. There is a need for further studies in terms of application length, effects on balance, and postural stability in patients submitted to surgery for ACL injury.

\section{Conflict of Interest:}

The authors declare that they have no conflict of interest.

\section{References:}

1. Kalawadia JV, Guenther D, Irarrázaval S, Fu FH. Anatomy and biomechanics of the anterior cruciate ligament. Anatomy and Genetics of Anterior Cruciate Ligament Injury. 2a.ed, Philadelphia, 2017.

2. Amis AA. Anterolateral knee biomechanics. Knee Surg Sports Traumatol Arthroscopy 2017; 25:1015-1023.

3. Pistone EA et al. Effects of early whole-body vibration treatment on knee neuromuscular function and postural control after anterior cruciate ligament reconstruction: a randomized controlled trial. J Rehabil Med. 2016; 48:880-886

4. Majewski M, Susanne H, Klaus S. Epidemiology of athletic knee injuries: a 10-year study. Knee. 2006; 13:184188.

5. Malempati C, Jurjans J, Noehren B, Ireland M, Johnson D. Current rehabilitation concepts for anterior cruciate ligament surgery in athletes. Sports medicine update. 2015. 38(11):689-696. 
6. Arliani GG, Astur DC, Kanas M, Kaleka CC, Cohens M. Lesão do ligamento cruzado anterior: tratamento e reabilitação. Perspectivas e tendências atuais. Revista Brasileira de Ortopedia. 2012;47(2):191-96

7. Konishi Y, Fukubayashi T, Takeshita D. Possible mechanism of quadriceps femoris weakness in patients with ruptured anterior cruciate ligament. Med Sci Sports Exerc. 2002;34:414-1418.

8. Williams GN, Chmielewski T, Rudolph K, Buchanan TS, Snyder-Mackler L. Dynamic Knee Stability: Current Theory and Implications for Clinicians and Scientists. J Orthop Sport Phys. 2001; 31(10):546-566.

9. Pietrosimone BG, Lepley AS, Ericksen HM, Gribble PA, Levine J. Quadriceps strength and corticospinal excitability as predictors of disability after anterior cruciate ligament reconstruction. J Sport Rehabil. 2013;22:1-6.

10. Krafft FC, Stetter BJ, Stein J, Ellermann A, Flechtnmacher J, Eberle C et al. How does functionality proceed in ACL reconstructed subjects? Proceeding of functional performance from pre- to six months post-ACL reconstruction. PLoS ONE. 2017; 12(5): e0178430.

11. Chmielewski TL, Wilk KE, Snyder-Mackler L. Changes in weight-bearing following injury or surgical reconstruction of the ACL: relationship to quadriceps strength and function. Gait Posture. 2002;16:87-95.

12. Bastian JD, Franz W, Klinik L. Whole Body Vibration Expedites and Improves Recovery of Anterior Cruciate Ligament (ACL) Rupture and Subsequent Arthroscopic Reconstructive Surgery. Sportsmedicine. 2014 56(7/8): 228.

13. Hiemstra LA, Webber S, MacDonald PB, Kriellaars DJ. Contralateral limb strength deficits after anterior cruciate ligament construction using a hamstring tendon graft. Clin Biomech. 2007; 22: 543-550.

14. Fu CL, Yung SH, Law KY, Leung KH, Lui PY, Siu HK et al. The effect of early whole-body vibration therapy on neuromuscular control after anterior cruciate ligament reconstruction: arandomized controlled trial. The American Journal of Sports Medicine. 2013. 41(4).

15. Risberg MA, Holm I, Myklebust G, Engebretsen L. Neuromuscular training versus strength training during first 6 months after anterior cruciate ligament reconstruction: a randomized clinical trial. Phys Ther. 2007, 87(6):737-750.

16. Wright RW, Haas AK, Anderson J, Calabrese G, Cavanaugh J, Hewett JE et al. Anterior Cruciate Ligament Reconstruction Rehabilitation:MOON Guidelines. Sports Health.2015; 7(3): 239- 243.

17. Berschin G, Sommer B, Behrens A, Sommer HM. Whole Body Vibration Exercise Protocol versus a Standard Exercise Protocol after ACL Reconstruction: A Clinical Randomized Controlled Trial with Short Term FollowUp. Journal of Sports Science and Medicine. 2014, 13:580-589.

18. Batista MAB, Walerstein LF, Dias RM, Silva RG, Ugrinowitsch C, Tricoli V. Efeitos do Treinamento com Plataformas Vibratórias R. bras. Ci e Mov.2007; 15(3):103-113.

19. Cardinale M, Wakeling J. Whole body vibration exercise: are vibrations good for you? Br J Sports Med. 2005;39:585-589.

20. Giombini A, Menotti F, Laudani L, Piccinini A, Fagnani F, Di Cagno A et al. Effect of whole body vibration frequency on neuromuscular activity in ACL-deficient and healthy males. Biol. Sport. 2015; 32:243-247.

21. García AE, Ortega PFB, Ruiz RJ, Carreño GF. Entrenamiento vibratorio. Base fisiologica y efectos funcionales. Ciencia y Tecnología para la Salud. 2005.262

22. Avelar NC, Ribeiro VG, Mezêncio B, Fonseca SF, Tossige-Gomes R, da Costa SJ et al. Influence of the knee flexion on muscle activation and transmissibility during whole body vibration. Journal of Electromyography and Kinesiology. 2013, 23:844-850.

23. Batista MAB, Walerstein LF, Dias RM, Silva RG, Ugrinowitsch C, Tricoli V. Effects of Training with Vibratórys Platforms. R. bras. Ci e Mov. 2007; 15(3): 103-113.

24. Pamukoff DN, Pietrosimone B, Lewek MD, Ryan ED, Weinhold PS, Lee DR et al. Whole-body and local muscle vibrationimmediately improve quadriceps function in individuals with anterior cruciate ligament reconstruction. Archives of Physical Medicine and Rehabilitation. 2016; 97: 1121-9. 